\title{
CARATERIZAÇÃO DOS PRINCIPAIS COMPARTIMENTOS GEOMORFOLÓGICOS E OS IMPACTOS AMBIENTAIS DECORRENTES DA OCUPAÇÃO DO RELEVO NO PERÍMETRO URBANO DO MUNICÍPIO DE ITUIUTABA/MG E ADJACÊNCIAS
}

\author{
Leda Correia Pedro Miyazaki ${ }^{(a)}$ \\ (a) Curso de Graduação e Pós-Graduação em Geografia, Faculdade de Ciências Intgradas do Pontal (FACIP), \\ Universidade Federal de Uberlândia (UFU), E-mail lecpgeo@ufu.br
}

Eixo: Uso e ocupação da terra e legislação ambiental

\begin{abstract}
Resumo
Objetiva-se com este trabalho identificar e caracterizar os principais compartimentos geomorfológicos do perímetro urbano do municipio de Ituiutaba/MG e área adjacêntes para relacioná-los com o processo de ocupação e os impactos oriundos dessa dinâmica. Para tanto, foram realizados alguns procedimentos metodológicos como o mapeamento geomorfológico a partir da utilização de fotografias aéreas, pesquisa bibliográfica, trabalhos de campo e gabinete. Como resultados foi possivel identificar quatro compartimentos geomorfológicos, sendo estes o dominio dos topos das colinas suavemente onduladas, dominio das vertentes concavas, convexas e retilíneas, dominio dos fundos de vale em berço e V, e por fim o dominio dos relevos residuais. Os impactos identificados foram erosões em forma de sulcos, ravinas e voçorocas, assoreamento, alagamento, solpamento, movimentos de massa.
\end{abstract}

Palavras chave: Relevo; Mapeamento; Ocupação; Impacto.

\section{Introdução}

Estudar a ocupação em áreas urbanas e seus impactos requer investigações minuciosas sobre a relação sociedade e natureza, uma vez que o "homem" ao ocupar determinado local gera transformações na paisagem e alterações em processos naturais que podem resultar em impactos ambientais negativos. Neste sentido, a Geomorfologia Urbana tem contribuido teórico-metodológicamente nos estudos sobre o processo de ocupação do relevo e os impactos oriundos dessa dinâmica, para elaborar documentos cartográficos e relatórios analíticos sobre a dinâmica dos processos naturais, a apropriação e ocupação do relevo e os impactos ambientais, para se pensar em um planejamento urbano e ambiental que considere a dinâmica da natureza afim de mitigar impactos negativos.

A sociedade ao se apropriar de um determinado local, inicia um processo de ocupação que afeta diretamente as formas do relevo, pois essa é uma das primeiras intervenções realizadas ao se implantar um loteamento. Uma das primeiras práticas é a retirada da vegetação existente, seguida pela terraplanagem 
que envolve tanto a construção de aterros, quanto o corte de taludes nas vertentes, para depois iniciar as construções.

Essas intervenções aceleram os processos naturais e podem ser exemplificadas por meio das erosões, que são resultantes da dinâmica da natureza. No entanto, as erosões podem ser aceleradas no momento que o "homem" retira a cobertura vegetal e deixa o solo exposto, rompendo o equilibrio dinâmico de infiltração e escoamento das águas pluviais nos topos e nas vertentes, acarretando o transporte de sedimentos e outros materiais até áreas de fundos de vale.

Dessa forma, para investigar a problemática aqui aqui apresentada, escolheu-se como local de estudo parte da área urbana do municipio de Ituiutaba/MG e adjacências, para identificar e caracterizar os principais compartimentos geomorfológicos e relacioná-las com o processo de ocupação e os impactos oriundos dessa dinâmica.

O município de Ituiutaba /MG possui 97.171 mil habitantes, cuja unidade territorial é de 2.598,04 $\mathrm{Km}^{2}$, e a área urbana está localizada no "Pontal do Triângulo Mineiro", na latitude $18^{\circ} 58^{\prime} 08^{\prime \prime} \mathrm{S}$, com longitude de 49 27' 54'” W Gr (Figura 1) e apresenta altitudes que atingem cerca de 769 m (IBGE, 2010).

Em relação à geologia é possível observar em alguns pontos afloramentos rochosos que compõem a Bacia Bauru cujas formações encontradas se referem ao Grupo Bauru, constituídas pelas Formações Marília e Adamantina e Formação Serra Geral, do Grupo São Bento (FERNANDES, COIMBRA, 1996).

Em relação aos aspectos geomorfológicos Baccaro (1990), diz que o relevo do Triângulo Mineiro é marcado por uma diversificação de compartimentos geomorfológicos oriundos das ações morfogenéticas do Terciário e do Quaternário, características presentes nos topos aplainados, nas camadas lateríticas, nos solos hidromórficos, nas lagoas e rampas côncavas de colúvios. O relevofoi fortemente esculturado pelas variações climáticas Terceário e Quaternário, cujas oscilações de clima úmido e seco favoreceram o rebaixamento generalizado do relevo, o que contribuiu para a formação das denominadas mesas e tabuleiros encontrados nesta região.

Para Santos e Baccaro (2004) os vestígios de uma alternância climática podem ser observados em algumas feições morfológicas encontradas na região, como por exemplo eventos evolutivos que contribuíram para a configuração de drenagem em anfiteatros e diferentes níveis de sedimentação, formando as cabeceiras de drenagem em anfitetro. Essas cabeceiras de drenagem são feições geomorofológicas que merecem atenção, pois estão predominantemente ligadas as nascentes dos principais rios, córregos e afluentes do municipio. fato este que merece atenção quanto a dinâmica dos processos naturais a ocupação do relevo e os impactos ambientais. 

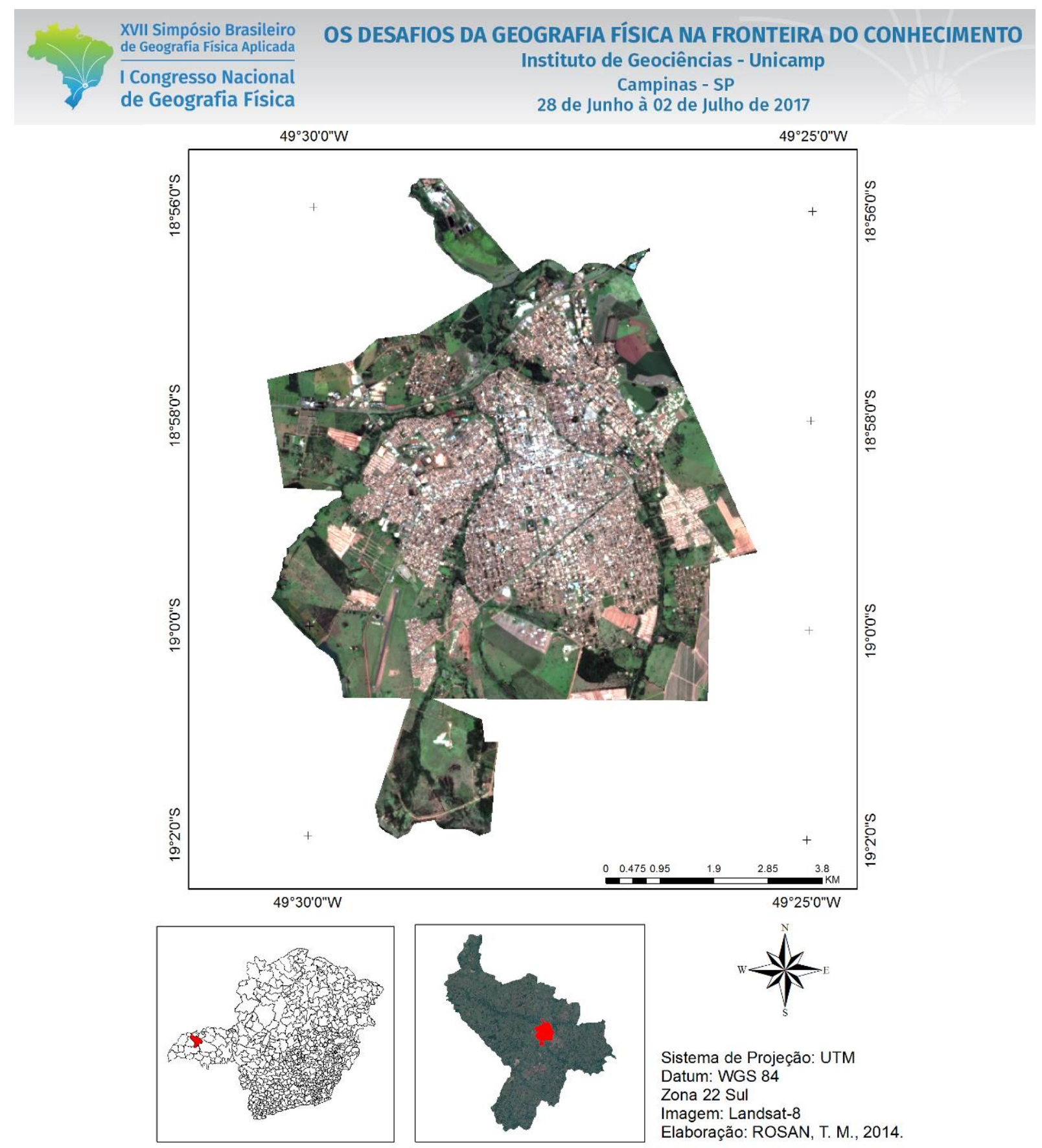

Figura 1. Localização da área urbana do município de Ituiutaba/MG

A temática abordada neste trabalho é considerada de grande relevância para a realizada local, uma vez que não havia nenhum mapeamento geomorfológico utilizando grande escala na área urbana do município para auxiliar o planejamento urbano e ambiental.

\section{Procedimentos metodológicos}


Revisão bibliográfica contemplou as pesquisas em gabinete, assim como a elaboração dos mapeamentos e análise dos produtos cartográficos para a elaboração dos textos analíticos.

O trabalho de campo foi fundamental durante a pesquisa, pois permitiu um conhecimento mais aprofundado da área de estudo, além de possibilitar a averiguação das informações espacializadas na carta dos compartimentos geomorfológicos.

A caracterização dos aspectos geológicos e geomorfológicos foi realizada a partir da descrição dos primeiros níveis de abordagem propostos por Ab' Saber (1969), conhecidos como Compartimentação Topográfica e Estrutura Superficial da Paisagem. O primeiro nível permitiu o entendimento da compartimentação topográfica regional, bem como a descrição das características predominantes das formas de relevo. E o segundo nível focou na obtenção de informações sistemáticas sobre a estrutura superficial da paisagem referente a todo o compartimento geomorfológico, podendo obter informações e dados referentes a cronogeomorfologia e as primeiras proposições interpretativas sobre a sequência dos processos paleoclimáticos e morfoclimáticos (AB' SABER, 1969).

Essa concepção teórico-metodológica norteou a aerofotointerpretação que permitiu a elaboração do esboço geomorfológico, para isso foram utilizadas três pares de fotografias aéreas na escala de 1: 60.000, cujo vôo foi realizado em 1962, da Força Aérea dos Estados Unidos (USAF) e um estereoscópico de mesa ou de espelho, obtidas na Companhia de Pesquisa de Recursos Mineiras (CPMR) unidade de Belo Horizonte/Minas Gerais e Instituto Brasileiro Geografia e Estatística (IBGE). Isso permitiu a visualização tridimensional das feições do relevo mais reluzentes.

Para identificação de cada uma das feições foram utilizadas chaves de interpretação das aerofotografias, onde se observou a variação e delimitação das texturas, das tonalidades, das rugosidades, dos padrões e dos diferentes tamanhos.

A visualização das feições geomorfológicas e conseqüentemente a extração seguiu uma sequiência didático-metodológica, sendo desenhados primeiramente os cursos d' águas, em seguida, delimitação dos divisores de água, os topos das colinas, as planícies aluviais, as cabeceiras de drenagem em anfiteatro e por fim, a caracterização das morfologias das vertentes, sendo identificadas como côncavas, convexas e retilíneas. Por fim, foram delineados os fundos de vales, no qual observou a forma em $\mathrm{V}$ ou em berço (NUNES, FREIRE, PERES, 2002).

A próxima etapa consistiu em transferir para a base digital topográfica e planialtimétrica georreferenciada obtida no site do IBGE para corrigir as distorções ortogonais que as fotografias aéreas possuem do centro para as extremidades, ou seja, as bordas (FUSHIMI, 2009). Assim, cada feição vetorizada, obtida através 
XVII Simpósio Brasileiro

de Geografia Fisica Aplicada

I Congresso Nacional

de Geografia Física
OS DESAFIOS DA GEOGRAFIA FÍSICA NA FRONTEIRA DO CONHECIMENTO

Instituto de Geociências - Unicamp

Campinas - SP

28 de Junho à 02 de Julho de 2017

da interpretação aerofotogeomorfológica, ocupou um layer específico para resultar no mapeamento dos compartimentos geomorfológicos.

Por fim, foram realizados trabalhos de campo para averiguação e registro das informações registradas no esboço geomorfológico.

\section{Resultados}

Compreender a relação sociedade e natureza nas áreas urbanas não é uma tarefa fácil, isso se deve a tamanha complexidade existente neste local. No entanto, um ponto de partida para tentar aprofundar os estudos é identificar e caracterizar aspectos físicos e os processos morfodinâmicos nas áreas urbanas atrelando essas informações com a questão da ocupação da terra e os impactos ambientais.

É possível verificar que o municipio de Ituiutaba/MG apresenta duas formas de relevo marcantes, sendo as colinas e os relevos tabuliformes, e foram estes dois relevos que permitiram espacializar os compartimentos geomorfológicos da área de estudo.

O relevo formado por colinas (Figura 2), podem ser definidos segundo Guerra (2006, p. 146), como "pequenas elevações do terreno com declives suaves e inferiores aos outeiros ${ }^{l}$. As colinas se parecem muito com as montanhas se diferenciando pelo fato de estarem isoladas e de apresentarem baixas altitudes". Predominantemente, o relevo de colinas encontrados no municipio de Itutiutaba é marcado por um topo amplo, suave e levemente ondulado. $\mathrm{Na}$ área urbana este compartimento do relevo é o mais apropriado para ocupação, pois exige pouco investimento de infraestrutura e terraplanagem. Este tipo de relevo é sustentado por rochas sedimentares da Formação Adamantina que afloram apenas em pontos específicos do município.

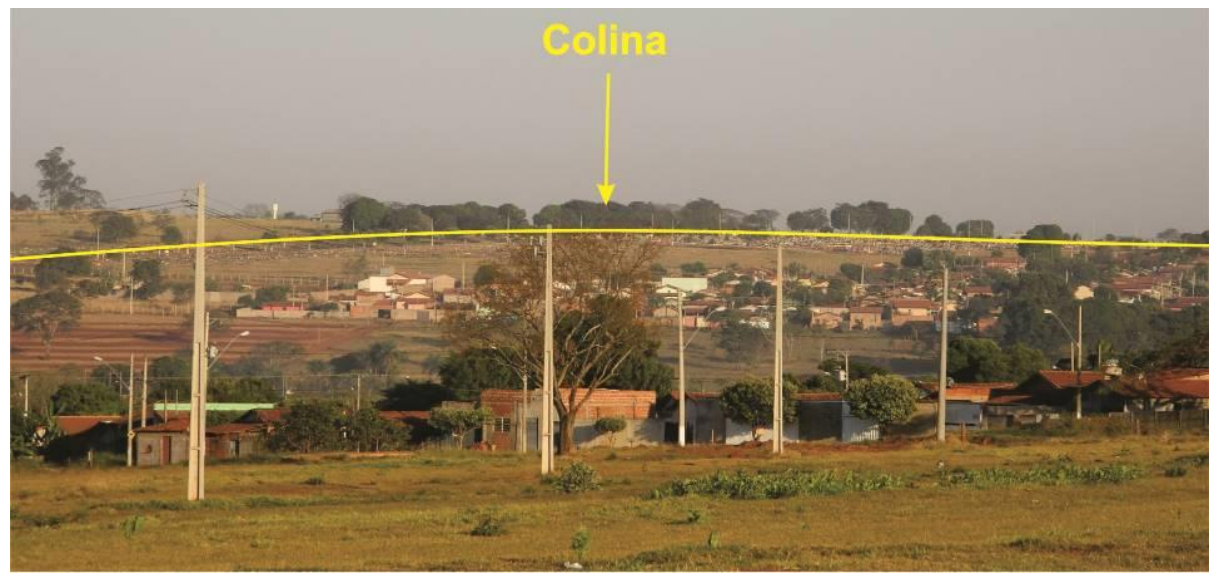

Figura 2. Relevo de colinas localizado no setor sudoeste da área urbana

\footnotetext{
${ }^{1}$ Pequenos morros cuja altitude média varia entre 50 e 100 metros (GUERRA, 2006, pag. 457)
} 
Outra forma de relevo que se destaca no municipio são os residuais do tipo tabuliformes (Figura 3). Esses relevos estão fortemente associados ao comportamento estrutural, cujas camadas sedimentares se apresentam horizontal ou subhorizontalmente e podem apresentar derrames basálticos ou camadas marcadas por forte resistência (CASSETI, 2001).

No municipio de Ituiutaba é possível identificar os relevos tabuliformes em cotas altimétricas superiores a 600 metros, cujas caraterísticas marcantes são os topos planos e vertentes com declividades acentuadas, chegando a declives superiores a $45^{\circ}$ de inclinação, a resistência litológica de determinadas camadas ocorre devido a presença do agente cimentante, sendo este o carbonato de cálcio, encontrados nos arenitos da Formação Marília.

Esse relevo se encontra nas áreas adjacentes do perímetro urbano e também do município de Ituiutaba, sendo predominantemente ocupado por vegetação característica do cerrado, que já vem enfrentando um processo de desmatamento devido ao uso indevido da área e a falta de políticas publicas que viabilize estes relevos com vegetação natural como áreas de preservação no município.

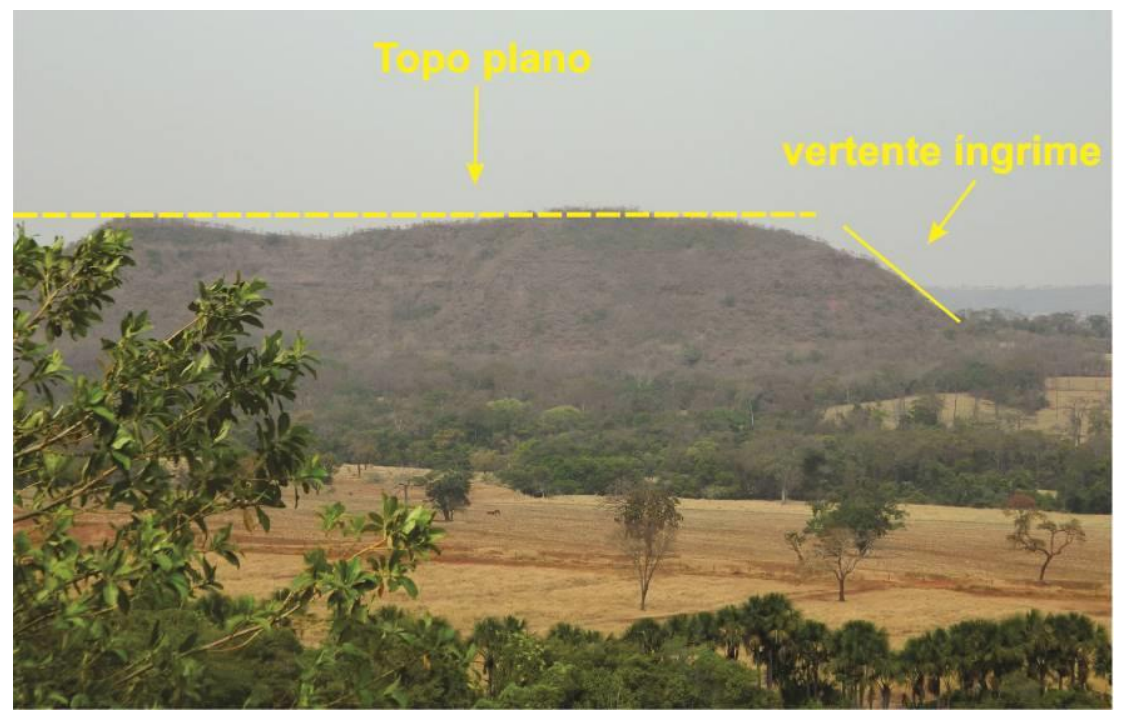

Figura 3. Relevo residual do tipo tabuliforme localizado no setor sul da área urbana

A partir da observação desses tipos de relevos, vinculados a forma de ocupação e associado a ausência de material cartográfico que permitisse o desenvolvimento de pesquisas com ênfase na escala de abordagem do local e a inserção de novas tecnologias aplicados aos procedimentos metodológicos, houve a necessidade de elaborar uma carta de compartimento geomorfológicos da área urbana utilizando fotografias aéreas e aerofotointerpretação. 


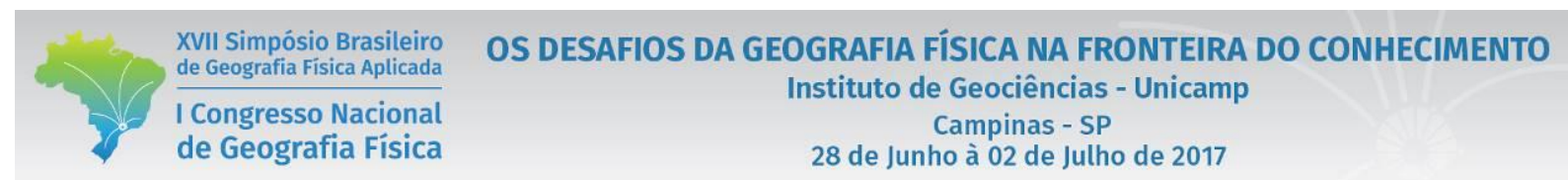

A elaboração da carta dos compartimentos geomorfológicos de parte da área urbana do município de Ituiutaba/MG e áreas adjacêntes (Figura 4) resultou na produção de um material inédito. A carta espacializou os principais compartimentos geomorfológicos, permitindo entender como os topos, as vertentes, os fundos de vale tanto das colinas, quanto dos relevos residuais foram apropriados e ocupados ao longo do tempo.

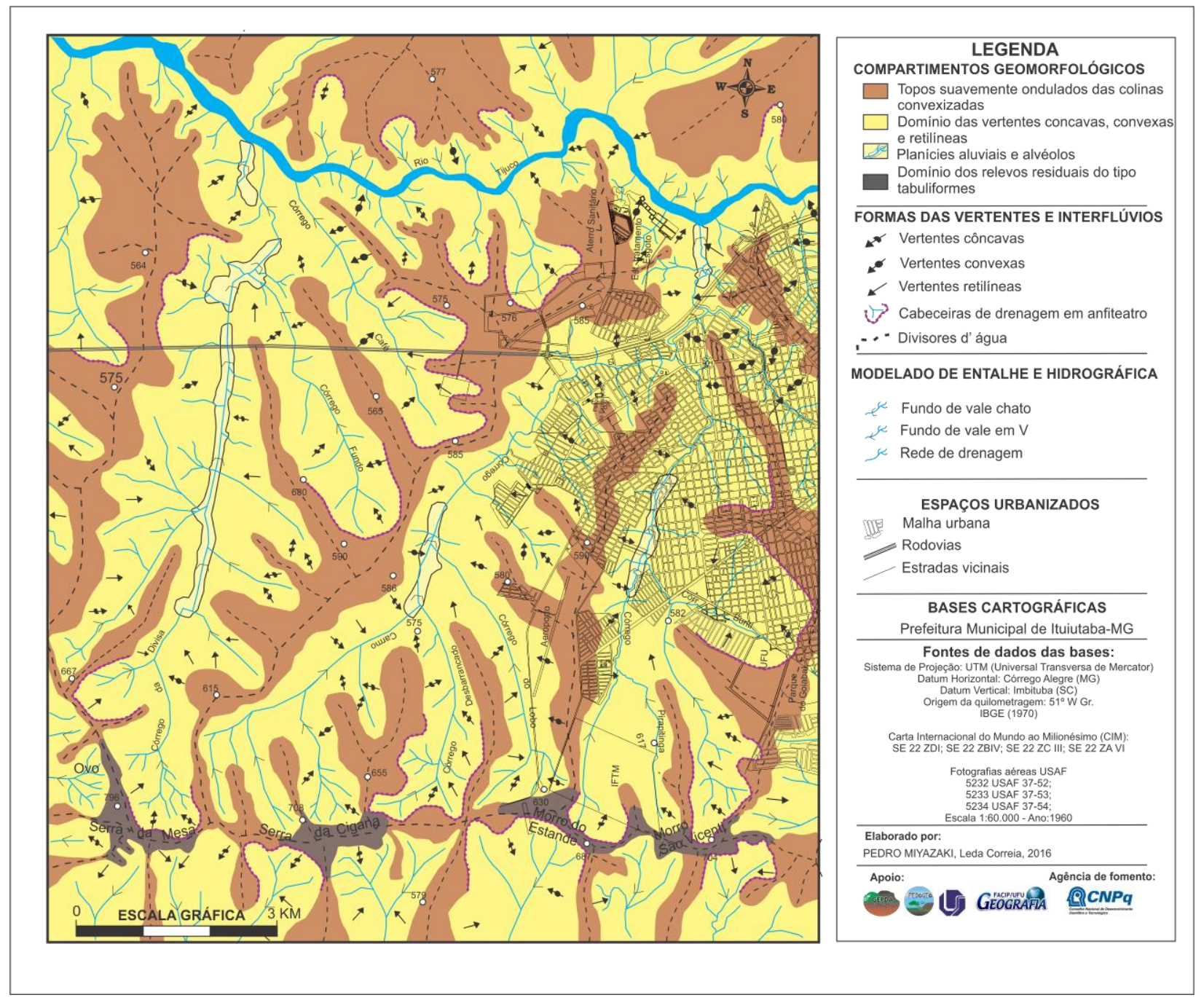

Figura 4. Carta dos compartimentos geomorfológicos de parte da área urbana do municipio de Ituiutaba/MG e áreas adjacêntes

Assim, foram identificados os seguintes compartimentos: os topos suavemente ondulados das colinas convexizadas; domínio das vertentes côncavas, convexas e retilíneas; os fundos de vale as planícies aluviais e alveolos e por fim o domínio dos relevos residuais do tipo tabuliformes.

O domínio dos topos apresentam caraterísticas que facilitam a ocupação urbana, uma vez que os topos são amplos e necessitam de "pequenas" obras de terraplanagem e infraestrutura voltada a estabilização de 


\section{OS DESAFIOS DA GEOGRAFIA FÍSICA NA FRONTEIRA DO CONHECIMENTO \\ Instituto de Geociências - Unicamp \\ Campinas - SP \\ 28 de Junho à 02 de Julho de 2017}

taludes, sendo na maioria das vezes o primeiro compartimento a ser ocupado. Os topos das colinas se apresentam bastante amplos, suaves e ondulados (Figura 05) e caracterizam-se por espigões divisores de água ramificados, dividindo as águas para as principais bacias hidrográficas na área urbana, sendo estas Bacia Hidrográfica do Córrego São José, Bacia Hidrográfica do Córrego Pirapitinga e Bacia Hidrográfica do Córrego do Carmo.

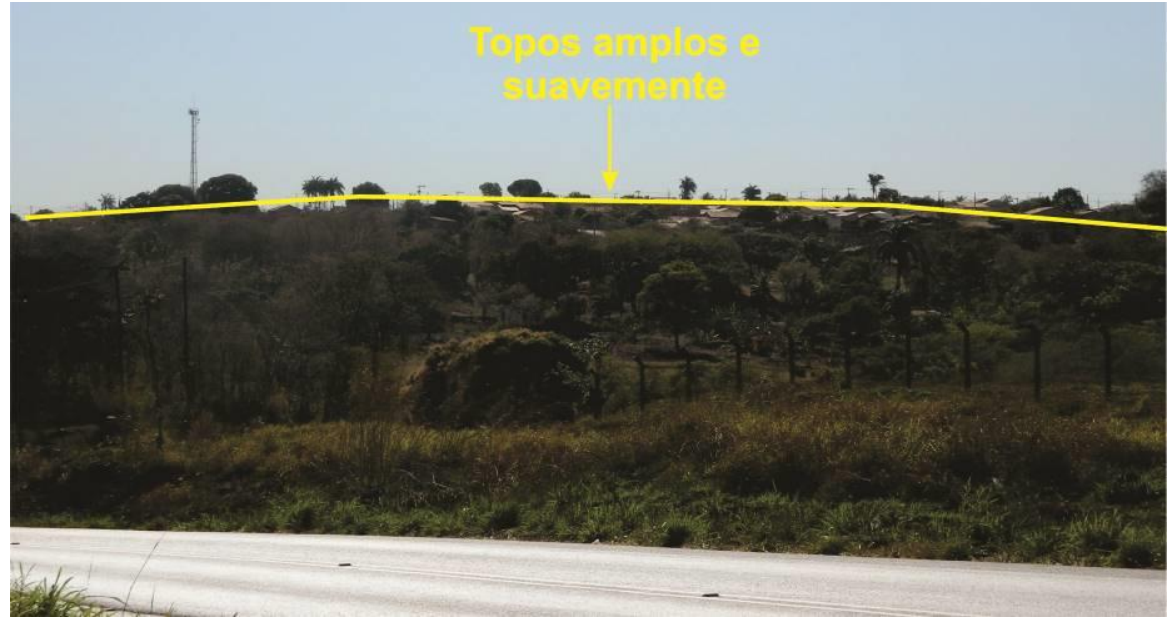

Figura 5. Topo amplo e suavemente ondulado identificado na área urbana do municipio de Ituiutaba/MG

O principal impacto identificado neste compartimento se refere ao solo exposto, pois com a implantação de loteamentos a primeira intervenção é a retirada da cobertura vegetal, seguida por terraplanagem e a construção de residências, prédios, ruas, avenidas entre outras. Essa intervenção deixa vários lotes com os solos expostos, assim como calçadas sem pavimentação e com rede de drenagem urbana ineficiente. Nos períodos de chuva o solo exposto "sofre" com o processo erosivo que desprende e transporta as partículas de solo, formando incisões lineares que dão origem as feições erosivas do tipos sulcos e ravinas. Além disso, quando o loteamento passa a ser intensamente ocupado, a impermeabilização do lote, ruas, calçadas acabam rompendo o equilibrio dinâmico de infiltração e escoamento, assim a maior parte das águas pluviais deixam de infiltrar e escoam para as áreas mais baixas do relevo, contribuindo e intensificando fenômenos momentâneos de inundação e alagamento nas áreas urbanas.

Em relação ao domínio das vertentes é possível identificar três formas, as vertentes côncavas, as convexas e as retilíneas (Figura 6). Cada morfologia possui uma função, sendo a vertente côncava capaz de dispersar as águas pluviais podendo formar pequenas erosões como sulcos e contribuir para o escomaneto difuso. Já as vertentes convexas possuem uma forma que possibilita a concentração das águas pluviais permitindo assim o acúmulo e infiltração. Por último as vertentes retilíneas que apresentam um comprimento de rampa, geralmente, bastante extenso o que facilita o escoamento superficial podendo dar origem as formas erosivas lineares. 


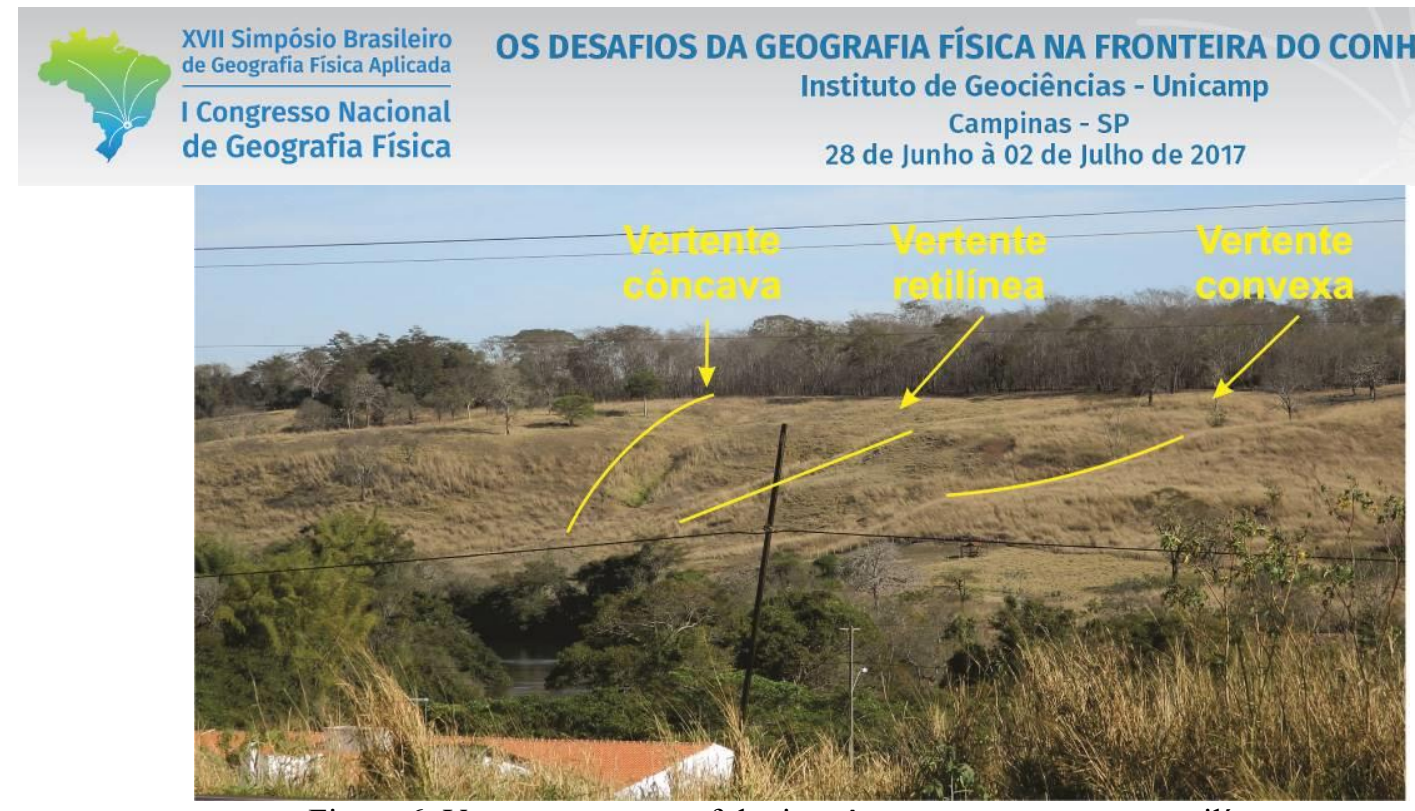

Figura 6. Vertentes com morfologias côncacavas, convexas e retilíneas

A ocupação das vertentes em relevos de colinas suaves é bastante comum e geralmente é o segundo compartimento geomorfológico a ser ocupado. As vertentes ao serem apropriadas e ocupadas são intensamente esculturadas, ou seja, "sofrem" uma intensa transformação na sua morfologia, pois exige obras de terraplanagem para deixar o terreno mais plano, além de cortes e aterros para serem edificadas, esse tipo de intervenção exige a construção de muros de arrimo para estabilizar as vertentes e um maior investimento do incorporador imobiliário e do futuro proprietário. Os principais impactos ligados a este compartimento são os movimentos de massa, sejam eles rápidos como os escorregamentos e queda de blocos, ou os lentos como o rastejo. Quando essas vertentes são ocupadas acabam sendo impermeabilizadas dificultando assim a infiltração das águas pluviais que por consequências disso acabam se concentrando nas vias públicas formando um "verdadeiro rio artificial", o que resulta no arraste de todo tipo de material que se encontra nos quintais das residencias, nas calçadas e nas ruas. $\mathrm{O}$ grande problema relacionado a isso é a questão da drenagem urbana que não suportam a quantidade e velociadade das águas pluviais que chegam em determinados pontos, resultando em alagamento momentaneos nas áreas de fundos de vale.

O domínio dos fundos de vale e das planicies aluviais e alveolos (Figura 07) representa o compartimento geomorfológico onde se encontra os vales em $\mathrm{V}$, sendo mais encaixados e os vales em berço, sendo mais largos e planos. As planicies aluviais, também conhecidas como planície de inundação podem ser definidas como a faixa do vale fluvial composta por sedimentos aluviais, ao longo do curso d'água que é influênciado periodicamente por inundações pelas águas de transbordamento dos córregos e rios (CHRISTOFOLETTI, 1980). 


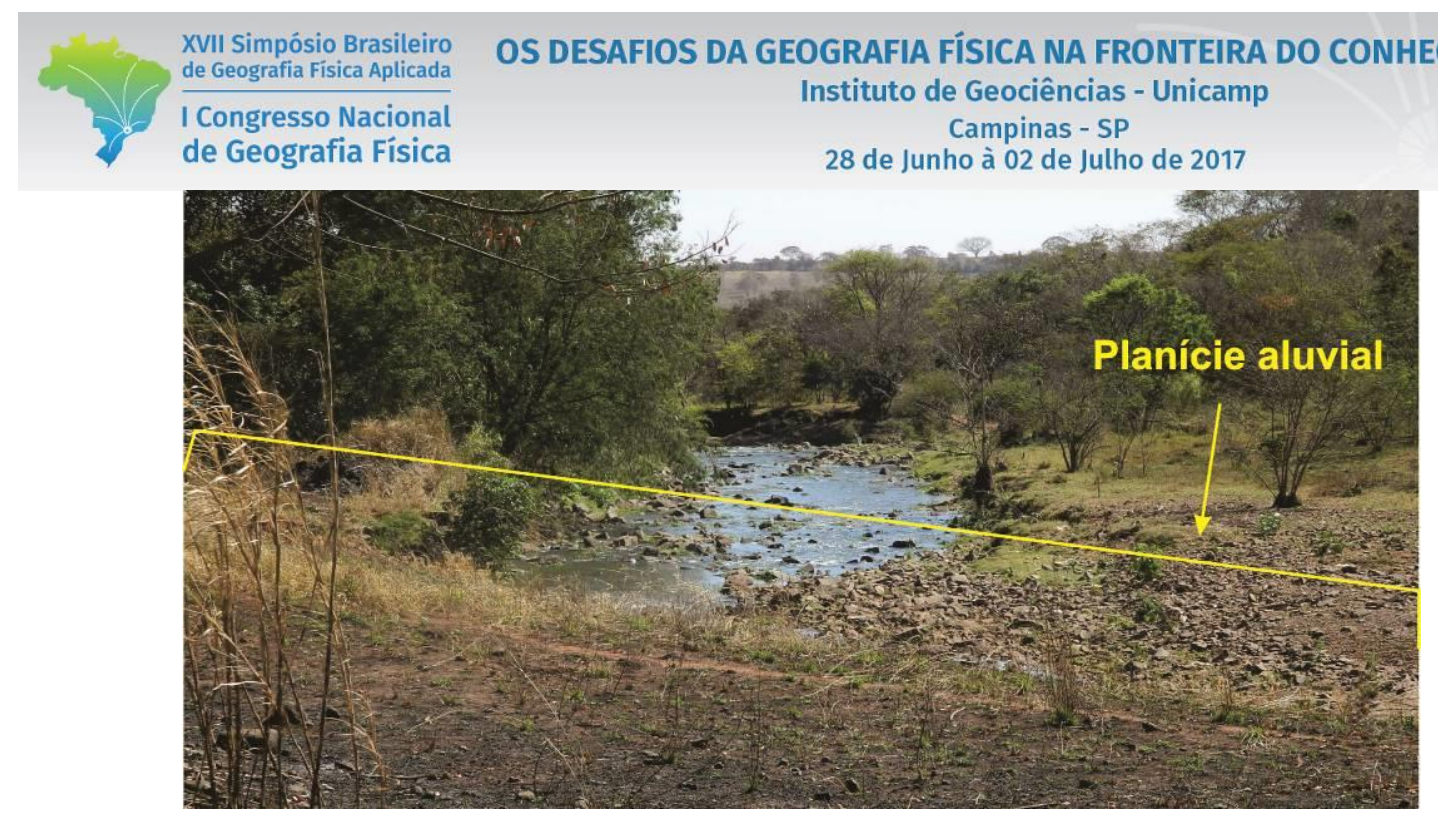

Figura 6. Planície aluvial identificada no Córrego da Pedreira

$\mathrm{Na}$ maioria das cidades os fundos de vales onde se encontram tanto as planìcies aluviais com morfologias de fundos de vale em berço, quanto os fundo de vale em $\mathrm{V}$ são retificados e canalizados alterando a dinâmica fluvial desse curso d'água, as planícies de inundação acabam sendo impermeabilizadas para construção de avenidas e ruas.

Quando os fundos de vales são ocupados dessa maneira provocam impactos ambientais gravíssimos, pois todas as águas pluviais que não infiltram nas áreas de topos e nas vertentes são direcionadas para este compartimento, assim o sistema de drenagem urbana ineficiente associada ao grande número de área impermeabilizada provoca a concentração dessas águas nos fundos de vale o que intensifica as enchentes, contribui para os alagamentos e ainda provoca o arraste de diferentes tipos de materiais para os cursos d' água formando bancos de materiais como os sedimentos e resíduos sólidos, além de imensos buracos nas vias, essas águas também atingem o interior das residências que se encontram próximas aos cursos d' água entre outros impactos.

O último compartimento geomorfológico são os relevos residuais que são encontrados ao redor da área urbana do município. Estes relevos ainda se encontra nas áreas periféricas ao perímetro urbano e atualmente grande parte desses relevos são ocupados pela pecuária extensiva, associada a vegetação natural do cerrado. Apresentam topos estreitos e vertentes íngremes o que dificulta a expansão da área urbana para esses locais. Neste tipo de relevo tabuliforme é possível encontrar várias cabeceiras de drenagem em anfiteatro, feições geomorfológicas que estão na maioria das vezes associadas as nascentes dos principais córregos que cortam a área urbana do município. Essas cabeceiras de drenagem possuem vertentes côncavas que contribuiem para a concentração de águas pluviais, permitindo assim a infiltração e o abastecimento do lençol freático e são responsáveis, juntamente com a vegetação, por preservar as nascentes no município de Ituiutaba/MG. 
No entanto, algumas práticas de lazer vem sendo desenvolvidas nestes tipos de relevos o que tem ocasionado impactos negativos, como por exemplo o ciclismo por meio de trilhas ao longo das vertentes que apresentam rampas de colúvios, pois as trilhas feitas pelas bicicletas acabam compactando o solo e formando incisões lineares que servem de locais de escomento das águas pluviais, dando origem aos sulcos e ravinas. Mas, não são apenas os ciclistas que estão provocando isso, o pisoteio do gado e as trilhas realizadas por motociclistas (motocross) estão acelerando ainda mais o processo linear. Além disso, o próprio desmatamento da vegetação natural tem deixado o solo exposto e susceptível a processos erosivos. Outro impacto identificado são as queimadas provocadas pela ação humana que tem destruído parte da cobertura vegetal das áreas de topos, vertentes e cabeceiras de drenagem desses relevos residuais do tipo tabuliformes.

\section{Considerações finais}

Diante da situação apresentada neste trabalho foi possível verificar que o mapeamento geomorfolófico dos compartimentos do relevo utilizando a escala de análise do local contribuiu para a localização, identificação e espacialização dos principais compartimentos do relevo, bem como as principais feições geomorfológicas. Por meio deste documento cartográfico foi possível caracterizar os topos, as vertentes e os fundos de vale tanto das colinas, quanto dos relevos residuais e verificar como cada um está sendo ocupado. Além disso, verificou-se que esses relevos estão sofrendo impactos decorrentes da expansão da malha urbana atreladas as técnicas utilizadas para implantação dos loteamentos entre outros. Mas, os impactos oriundos da intervenção do ser humano não para por aí, as atividades de lazer e as práticas que envolve o desmatamento e a queimada urbana e rural também vem provocando impactos ambientais nas cabeceiras de drenagem em anfiteatro, onde estão localizadas as nascentes dos principais córregos e rios do município. O mais alarmante é que esses cursos d’águas fazem parte da bacia hidrográfica que fornece água para a população local.

\section{Agradecimentos}

Agradecemos as agências de fomentos CNPq por financiar o projeto de mapeamento geomorfológico da área urbana de Ituiutaba e à FAPEMIG por custear apresentações e divulgações dos resultados.

\section{Bibliografia}

AB'SABER, A.A. Um conceito de geomorfologia a serviço das pesquisas sobre o quaternário. Geomorfologia, S. Paulo, Igeog-USP (18), 1969. 


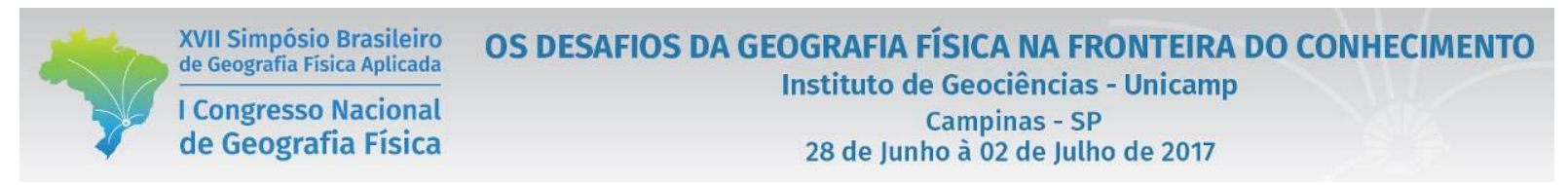

BACCARO, C. A. D.e. Estudo dos processos geomorfológicos de escoamento pluvial em área de CerradoUberlândia -MG. EDUSP, São Paulo, Tese de Doutorado, 1990.

BACCARO, C. A. D.e, SANTOS, L. d. Caracterização geomorfológica da bacia do rio Tijuco. Revista Caminhos de Geografia. 1 (11), p. 1-21, fev., 2004.

BACCARO, C. A. D. ; FERREIRA, I. L.a ; ROCHA, M. R. ; RODRIGUES, S. C . Mapa Geomorfológico do Triangulo Mineiro. Sociedade \& Natureza, Uberlândia, v. 13, n.25, p. 115-

$127,2001$.

CASSETI, V. Elementos de Geomorfologia. Gias, Editora da UFG, $1^{\text {a }}$ edição, 1990

CHRISTOFOLETTI, A. Geomorfologia. São Paulo, Edgard Blucher, $2^{a}$ edição, 1980.

GUERRA, A. T.; GUERRA, A. J. T. Novo dicionário geológico-geomorfológico. 5a edição. Rio de Janeiro, Bertrand Brasil, 2006

FERNANDES, L. A. ; COIMBRA, A. M. Revisão estratigráfica da parte oriental da Bacia Bauru (Neocretaceo). Revista Brasileira de Geociências. 30 (4), p. 717-728, dez., 2000.

FUSHIMI, M.. Mapeamento Geomorfológico do Município de Presidente Prudente - SP. Monografia de Bacharelado. 2009 - Universidade Estadual Paulista, Faculdade de Ciências e Tecnologia, Campus de Presidente Prudente, 2009.

CENSO DEMOGRÁFICO 2010. Características gerais da população, religião e pessoas com deficiência.

Rio de Janeiro: IBGE, 2012. Acompanha 1 CD-ROM. Disponível em: <ftp://ftp.ibge.gov.br/Censos/Censo_Demografico_2010/Caracteristicas_Gerais_Religiao_Deficiencia/caracteristicas _religiao_deficiencia. pdf>. Acesso em: mar. 2013.NUNES, FREIRE, PERES, 2002.

PEDRO MIYAZAKI, L. C. Espacialização dos compartimentos geomorfológicos de parte da área urbana e Ituiutaba/MG. ANAIS XVIII Encontro Nacional de Geógrafos, 2016. São Luiz , Maranhão. XVIII Encontro Nacional de Geógrafos: UFMA, 2016.

ROCHA, M. R.; BACCARO, C. A. D. ; FERREIRA, I. L. ; RODRIGUES, S. C. . Mapeamento Geomorfológico do Triângulo Mineiro. In: $8^{\circ}$ Encuentro de Geógrafos de América Latina, 2001, Santiago - Chile. $8^{\circ}$ Encuentro de Geógrafos de América Latina. Santiago: Universidad de Chile, 2001. v. 2. 